\title{
Cryopreservation of the Bovine Oocyte: Current Status and Perspectives
}

\author{
C Díez, M Muñoz, JN Caamaño and E Gómez \\ Centro de Biotecnología Animal-SERIDA, Gijón, Spain
}

\section{Contents}

This review presents some of the most noticeable aspects related with the oocyte cryopreservation procedures, emphasizing their evolution in the bovine, which points towards the critical points determining the reduced survival rates of female gametes to freezing and vitrification. Factors such as the maturation status, the cytoskeleton and membrane sensitivity, the role of the cumulus cells, the impact of the cryoprotectants agents and the protocols utilized and the future of this tool have been extensively reviewed.

\section{Introduction}

Since the middle of the last century, in parallel with the development of assisted reproductive technologies, gametes and embryos have been cryopreserved, allowing modifying domestic animal breeding programmes. These technologies have accelerated the progress of genetic improvement, and the worldwide distribution of germplasm (Holt 2008). Gradually, these technologies have also started to be used in conservation of endangered species (Prentice and Anzar 2011). Despite of all these efforts invested, in the case of the oocytes, advances are rather slow, being the main problems the lack of consistency of the results among groups (Liebermann and Tucker 2002), as well as differences in survival rates after warming between species, development stages that were cryopreserved and embryo and oocyte quality (Prentice et al. 2011).

After cryopreservation, the oocyte presents compromised developmental competence. Optimal cryopreservation protocols should be adapted to individual species requirements, which present large variations in gamete size, permeability and sensitivity to cryoprotective agents (CPAs). Vitrification reduces oocyte damage by increasing cooling and warming rates, avoiding ice formation. Moreover, the use of minimal volume techniques allows reducing injuries associated to CPA toxicity, leading to increased survival rates after warming (Arav et al. 2002).

Although cryopreservation of bovine oocytes is challenging, some of the most encouraging results among domestic species have been obtained in cattle (Dinnyés et al. 2000; Vieira et al. 2002; Chian et al. 2004), and offspring have been born from vitrified oocytes after in vitro fertilization (IVF) and culture (Vajta et al. 1998; Papis et al. 2000; Vieira et al. 2002). Thus, in 1998, Vajta et al. reported a $25 \%$ of blastocyst rate on Day 8 following oocyte vitrification using the open pulled straw method.

\section{Why Do We Cryopreserve Oocytes?}

Preservation of oocytes would enable a more efficient management of livestock and laboratory animal species.
Cryopreserved oocytes can be stored until the female expresses her genetic merit, and the appropriate mate can be performed. Efficient cryopreservation of oocytes would also facilitate implementation of assisted reproduction procedures in oocytes recovered from females that die accidentally (Ledda et al. 2001; Woods et al. 2004; Checura and Seidel 2007; Pereira and Marques 2008; Prentice et al. 2011). On the other hand, in human, the successful preservation and storage of female gametes would allow the advancement of assisted reproductive technology and medicine, limiting ethical problems by avoiding the embryo cryopreservation. Therefore, there is a need of successful cryopreservation procedures for oocytes.

\section{Why bovine oocytes do not resist cryopreservation?}

Development rates of cryopreserved oocytes are lower than those shown by fresh oocytes (Table 1) not only in cows (Vajta et al. 1998; Dinnyés et al. 2000; Schmidt et al. 2004), but also in many other species such as mouse (Rall and Fahy 1985; Lane and Gardner 2001), pigs (Rojas et al. 2004; Gupta et al. 2007), humans (Chung et al. 2000) or horses (Tharasanit et al. 2006).

Oocytes suffer considerable morphological and functional damage during cryopreservation. The extent of the injury depends on factors that are related with the species, the developmental stage, and the oocyte's ability to fully or partially repair damage and continue normal development (Fuller and Paynter 2004). Drawbacks in cryopreservation of mammalian oocytes can be summarized as follows (for review, see Dinnyes et al. 2007; Saragusty and Arav 2011):

1 Their complex structure: oocytes are among the largest mammalian cells, with a low surface-tovolume ratio, making them very sensitive to chilling and highly susceptible to intracellular ice formation.

2 The plasma membrane of oocytes at the MII stage has a low permeability coefficient, making the movement of CPAs and water slower.

3 The zona pellucida acts as a barrier to movement of water and CPAs.

4 The freezing/thawing process induces a premature cortical granule exocytosis, leading to zona pellucida hardening and impairing sperm penetration.

5 Oocytes have high cytoplasmic lipid contents that increase chilling sensitivity.

6 After maturation, the MII oocyte shows chromosomes aligned in the meiotic spindle in a very problematic stage for cryopreservation; temperature and CPA sensitivity of the spindle and microtubules provoke cytoskeleton disorganization, and chromosome and DNA abnormalities. 
Table 1. Cleavage (compared with control fresh oocytes) and blastocyst rates after in vitro fertilization of bovine oocytes vitrified at GV or MII stage, following different protocols

\begin{tabular}{lcccc}
\hline Oocyte stage & Cryopreservation method & Cryprotectant agent & \% Cleav vs control & Authors \\
\hline GV & OPS & EG + DMSO & 25 vs 90.7 & 0 \\
MII & OPS & EG + DMSO & 32.8 vs 90.7 & Diez et al. (2005) \\
MII & OPS & EG + DMSO & 42.8 vs 70.2 & Diez et al. (2005) \\
MII & Flexipets & EG + DMSO & 16.2 vs 70.2 & Morató et al. (2008a) \\
MII & Cryotop & EG + DMSO & 46.1 vs 66.9 & Morató et al. (2008b) \\
MII (denuded) & Cryotop & EG + PROH & 68.6 vs 83.1 & 2.4 \\
MII (denuded) & Cryotop & EG + DMSO & 69.8 vs 83.1 & 1.7 \\
GV & OPS & EG + DMSO & Chian et al. (2004) \\
\hline
\end{tabular}

DMSO, dimethylsulphoxide; EG, ethyleneglycol; GLY, glycerol; GV, germinal vesicle; OPS, open pulled straws

Cleav: cleavage rate on Day 3; \% Blast: blastocyst rate on Day 8.

7 Oocytes are also more susceptible to damaging effects of reactive oxygen species (ROS); thus, cryopreservation results in the generation of ROS that can affect viability and developmental competence.

\section{What Aspects can be Considered for cryopreserving bovine oocytes?}

\section{Maturation stage of the oocyte}

Although many works have been conducted to determine optimal meiotic stage for oocyte cryopreservation, results are still controversial (Magnusson et al. 2008).

For in vitro processing, oocytes are collected from secondary follicles at the germinal vesicle $(\mathrm{GV})$ stage. During the meiotic transitions, there will be cytoplasmic and perivitelline space changes, alterations in the synthesis and storage of proteins and RNA, reorganization and migration of organelles and cortical granules and morphological changes in cumulus cells (Mermillod et al. 2000). In an in vitro programme, the success of this process is much more difficult to achieve than nuclear maturation, and the inadequate cytoplasmic maturation may seriously compromise the viability of the oocyte.

Maturation stages ranging from GV (Hochi et al. 1998; Lim et al. 1999; Rojas et al. 2004) through MII (Otoi et al. 1995; Hochi et al. 1998, 2001; Men et al. 2002, 2003; Diez et al. 2005) have been described as the most favourable phases for vitrification. However, other studies report that the ability of oocytes to survive cryopreservation is not affected by the meiotic stage in which the oocyte was cryopreserved (Le Gal and Massip 1999). Differences among these studies can be partially explained by the use of different CPAs because of the selective tolerance of oocytes at different meiotic stages (Zeron et al. 1999).

The main damage in MII vitrified oocytes is the meiotic spindle disorganization followed by microtubule depolymerization (Aman and Parks 1994; Shaw et al. 2000; Men et al. 2002; Rojas et al. 2004; Prentice et al. 2011). Vitrification of GV oocytes might overcome this problem because the meiotic spindle is not organized yet. However, permeability to CPAs and water in GV oocytes are lower than that in MII stage (Pedro et al. 1997; Agca et al. 1998). Moreover, GV oocytes are extremely sensitive to cryopreservation, as a result of damage inflicted at the cytoplasmic membrane level (Allworth and Albertini 1993; Arav et al. 1996; Men et al. 2002) and gap junctions integrity, which disrupts communication between cumulus cells and oocytes (Diez et al. 2005). Zhou et al. (2010) showed that oocytes vitrified at the $\mathrm{GV}$ stage exhibited cleavage and blastocyst rates significantly higher than vitrified MII oocytes. They hypothesized that the increase in volume associated with cumulus cells expansion during maturation can be one of the reasons of the decreased viability of cryopreserved MII oocytes. Also, the higher permeability to water and solutes of MII oocytes compared with GV state (Pedro et al. 1997; Agca et al. 1998) could induce changes of cell volume during CPA addition and dilution, leading to increased intracellular CPA concentrations in MII than in GV oocytes.

Inhibition of meiosis is thought to reproduce the period necessary for the achievement of the cytoplasmic maturation, allowing the oocyte to synthesize and store mRNA and protein. The use of meiotic inhibitors, such as roscovitine or butyrolactone, allowed oocytes to improve developmental competence without reducing blastocyst rates (Mermillod et al. 2000; Diez et al. 2005), and their effects have been analysed on oocyte survival to vitrification without positive results (Albarracín et al. 2005; Diez et al. 2005). Moreover, high oocyte degeneration rates were shown in vitrified oocytes submitted to a meiotic arrest, independently on the timing of the vitrification step (Diez et al. 2005).

\section{Cellular membrane}

The permeability of the plasma membrane affects cell survival after vitrification (Zeron et al. 2002; Jin et al. 2011). Cholesterol is present in the plasma membrane, and its level and the ratio cholesterol/phospholipids of membranes determine the membrane fluidity and the chilling sensitivity (Horvath and Seidel 2006).

There are two pathways for the movement of water and cryoprotectants across the plasma membrane: simple diffusion through the lipid bilayer, and facilitated diffusion through channels (Jin et al. 2011). Water and CPAs move slowly across the plasma membrane in mouse oocytes and early cleavage-stage embryos, principally by simple diffusion. However, in morulae, water, ethyleneglycol (EG), glycerol (GLY) or dimethylsulphoxide (DMSO) move quickly, mainly by facilitated diffusion via channels. The permeability of the plasma membrane and/or other cryobiological properties might also differ between species. In bovine, the permeability 
of oocytes to water and CPAs is lower than that of morulae and blastocysts (Széll et al. 1989; Ruffing et al. 1993; Agca et al. 1998). When the movement of water and CPAs depends predominantly on simple diffusion across the plasma membrane, flow rates are reduced and affected by the temperature. Conversely, diffusion via channels implies a higher membrane permeability and higher independence on the temperature.

There have been many attempts to change plasma membrane composition during in vitro procedures to improve cryopreservation of embryos and gametes (Arav et al. 2000; Zeron et al. 2002; Seidel 2006). The addition of unsaturated fatty acids to ewe oocytes by electrofusion of liposomes to the oolemma decreased the oocyte's sensitivity to chilling (Zeron et al. 2002). The modification of the lipid phase transition temperature following phosphatidylcholine or dipalmitoylphosphatidylcholine transfer to matured eggs also reduced chilling sensitivity (Zeron et al. 2002). In other studies, the addition of linoleic acid albumin to culture media improved cryosurvival of enucleated oocytes (Hochi et al. 2000). Moreover, oocyte cryosurvival and early cleavage rates could be improved by incubation with cholesterol-loaded cyclodextrin before cryopreservation (Horvath and Seidel 2006). These modifications of lipid membrane composition led to significant improvements in post-thaw oocyte viability and early cleavage, but blastocyst rates still remain lower than those obtained from non-cryopreserved oocytes (Ledda et al. 2007).

\section{Cytoskeleton}

One of the cellular components often damaged during cryopreservation is the cytoskeleton (Prentice et al. 2011). Physico-chemical conditions during cryopreservation can produce irreversible loss of spindle microtubules (Vincent et al. 1990; Rho et al. 2002; Mullen et al. 2004; Albarracín et al. 2005; Tharasanit et al. 2006). Rupture of the cytoskeleton may be intrinsic to the changes in shape and shrinkage associated to cryopreservation, leading to irreversibly changes in the structure of the cytoskeleton. Moreover, highly concentrated CPAs may lead to injury of the meiotic spindle (Chen et al. 2000; Mullen et al. 2004), and although the meiotic spindle may re-polymerize after thawing or warming if temperature recovers, the consequences of cryopreservation on the spindle function remain to be accurately established. At the GV stage, cryopreservation may also induce defective spindle assembly, which may affect chromosome segregation in meiosis I during the in vitro maturation (IVM) of the thawed GV oocytes (Saragusty and Arav 2011).

Cytoskeleton stabilizing components may improve the cryotolerance of mature and immature oocyte. Thus, cytochalasin B (CB), cytochalasin D (CD) and colchicine were used in culture media prior to cryopreservation. In MII oocytes, $\mathrm{CB}$ reduces damage to microtubules and may enhance spindle microtubule stabilization during vitrification (Rho et al. 2002). In $\mathrm{GV}$ oocytes, as no organized meiotic spindle is present, the relaxant effect of $\mathrm{CB}$ may preserve the function of gap junctions between oocyte and granulosa cells allowing a better (faster and more uniform) penetration of CPAs (Vieira et al. 2002). Also, the use of taxol (a microtubule stabilizer) improved post-thawing development of vitrified mouse oocytes (Park et al. 2001) and improved the spindle morphology after warming in bovine (Morató et al. 2008c).

\section{Cumulus cells}

Cumulus cells play a fundamental role during the oocyte maturation. These cells and the oocyte are functionally and physically connected, establishing interactions that are fundamental for the oocyte development competence ( $\mathrm{Li}$ et al. 2006). The presence of cumulus cells also minimizes the release of cortical granules, preventing premature zona hardening, thus maintaining the fertilization capacity of the oocyte after cryopreservation (Vincent et al. 1990). Thus, successful cryopreservation of immature oocytes would depend on the ability to preserve the viability of the female gamete together with the structural and functional integrity of the cumulusoocyte complex (Modina et al. 2004).

Different approaches show that the presence of a whole cumulus-oocyte complex improves oocyte survival rates after vitrification warming in GV oocytes. Such a beneficial effect was not observed among MII oocytes (Zhou et al. 2010), which showed similar developmental rates independently of the presence of cumulus cells. The same authors showed that whole cumulus-enclosed GV oocytes survived vitrification and developed at higher rates than MII cumulus-enclosed oocytes (Zhou et al. 2010). Authors hypothesized that this disparity could be due to an increased cell volume associated with cumulus expansion during maturation, together with differences in water and solute permeability between MII than GV bovine oocytes (Wang et al. 2010). In buffalo, the presence of cumulus cells significantly reduced cleavage rates of MII oocytes following vitrification (Gasparrini et al. 2007). It should be kept in mind that the exposure to CPAs results in a lose of the cumulus cells connection with the oocyte (Diez et al. 2005). In contrast, Bogliolo et al. (2007) reported that the presence of cumulus cells did not improve cryosurvival of ovine immature oocytes. Whether cumulus cells are necessary during cryopreservation of immature oocytes is still debated, as species-specific differences may underlie (Fujihira et al. 2005; Ruppert-Lingham et al. 2006).

\section{Freezing vs vitrification? Why?}

Cryopreservation strategies aim to reduce cell damage by optimizing both CPA concentrations and coolingwarming rates. Consequently, the design of an improved cryopreservation protocol should take into account the whole sequence of events occurring during cryopreservation. Three major methods have been used for oocyte cryopreservation: conventional slow-rate freezing, classical vitrification in straws and ultrarapid vitrification.

Conventional slow freezing consists of the application of controlled cooling rates, which allows cell dehydration by means of extracellular and intracellular fluid exchange. This technique has been used successfully to freeze oocytes of species with low sensitivity to chilling 
(Shaw and Jones 2003; Agarwal 2009) and has been used to freeze human oocytes and embryos. However, poor results have been reported for species more sensitive to chilling (pig, cattle, sheep and horse). Slow freezing commonly follows the next steps (for review see Dinnyes et al. 2007): (i) addition of a CPA to the cells-containing solution; (ii) seeding the samples a few degrees above the freezing point of the cell suspension; (iii) cooling the cells to a low temperature for storage; (iv) thawing the cells; and (v) removing the CPA from the cells and rehydration. Several of the above steps produce water flow through the cell membrane, which can lead to shrinkage and swelling events capable of causing damage or cell death. The extent of this shrink/swell response varies for each cell type depending on its permeability, size and also depending on the CPA used (Shaw and Jones 2003). During the cooling process, if cells are cooled too rapidly, water does not flow out the cells fast enough to maintain the osmotic equilibrium. The cells become then increasingly supercooled and eventually freeze intracellularly in a phenomenon that is lethal for cells (Shaw and Jones 2003; Dinnyes et al. 2007; Saragusty and Arav 2011). If cooling is relatively slow, the cells will rapidly lose water, leading to a concentration of intracellular solutes able to neutralize the supercooling effects.

Vitrification cools cells without glass formation, by supercooling the solution and transforming it into a 'vitreous', amorphous state (Prentice and Anzar 2011). When dealing with cryopreservation of mammalian embryos, and especially oocytes, vitrification has become a viable and promising alternative to traditional approaches (Kuwayama 2007). Vitrification avoids the toxic and osmotic injuries of crystallization. Once the specimen is cooled below a temperature called the 'glass transition temperature', crystallization is not possible. However, limited success has been reported on vitrification of bovine cumulus-oocyte complexes, because of the above-explained reasons. The sudden exposure to high concentrations of CPAs is toxic to oocytes; to avoid these deleterious effects, the exposure time of oocytes to cryoprotectants is shortened by a preincubation in one solution that contains a lower concentration of permeating CPAs than the final vitrification solution (Vajta et al. 1998). Vitrification considers three main factors (for review, see Shaw and Jones 2003; Saragusty and Arav 2011): (i) cooling rate, that depends on the use of liquid nitrogen or liquid nitrogen slush, the container, the thermal conductivity and the solution composition; (ii) viscosity of the medium in which the oocytes are suspended: defined by the concentration and behaviour of CPAs and other additives (the higher the concentration of CPAs, the higher the glass transition temperature, thus lowering the chance of ice nucleation and crystallization); different CPAs and other additives have different toxicity, penetration rate, and transition temperature; and (iii) the volume of the vitrification solution: the smaller the volume, the higher the probability of vitrification.

Classical vitrification 'in straw' procedures have been replaced by ultrarapid vitrification techniques that reduce the ratio oocyte/volume of the CPA solution and increase the cooling/warming rates. Many tech- niques have been developed to reduce the volume of the sample (for review see Saragusty and Arav 2011). Among these new devices, open pulled straws (OPS), cryoloops, microdrops, flexipet-denuding pipettes, electron microscope copper grids, cryotips or cryotops are the most commonly used. The Cryotop method allows obtaining noteworthy viability rates in human (Kuwayama 2007), bovine (Chian et al. 2004), ovine (Ebrahimi et al. 2011) and porcine (Liu et al. 2008) oocytes.

Up to now, limited attention has been given to the rehydration conditions. In fact, rehydration is as important as other steps of the entire procedure, because removal of the intracellular cryoprotectant and reestablishment of the water content causes osmotic stress and re-crystallization (Seki and Mazur 2008).

\section{Cryoprotectant solution}

Permeating or non-permeating CPAs has been widely tested to minimize toxic, osmotic and other injuries during cryopreservation. The major penetrating CPAs used in oocyte cryopreservation are EG, GLY, DMSO, propylene glycol (PrOH) and acetamide (Shaw and Jones 2003). Ethyleneglycol is usually combined with DMSO for freezing and vitrification of gametes (Paynter 2005). The shrink/swell response of murine oocytes was similar in the presence of DMSO and PrOH; EG permeated the cells quickly, and GLY resulted in extreme shrinkage and little permeation of the cryoprotectant (Paynter 2005). Therefore, GLY is not a suitable cryoprotectant for preservation of mature oocytes. The shrink/swell response varies with the temperature; the higher the temperature, the less the shrink response of the oocytes and the less the osmotic stress. However, temperature enhances the potential CPA toxicity, and both variables must be balanced to design protocols for exposure to cryoprotectant. The extent of the effect of temperature depends on the type of cryoprotectant, as demonstrated by the differences in permeability of murine oocytes to EG and DMSO at a range of temperatures (Shaw and Jones 2003).

Ethyleneglycol and DMSO were shown to cause a rise in mouse oocyte intracellular calcium, inducing cortical granule exocytosis and zona hardening (Larman et al. 2006). When calcium was removed from the vitrification solution, this effect was diminished, making it sperm penetration possible (Larman et al. 2006). It was also reported a toxic effect of DMSO on bovine oocytes (Arav et al. 1993), although other researchers reported successful oocyte vitrification with DMSO alone or associated with other cryoprotectants (Vieira et al. 2002). Thus, Yamada et al. (2007) showed differences among maturation rates of immature oocytes vitrified in the presence of EG + DMSO at different concentrations. The highest maturation rates were obtained after the exposure for $30 \mathrm{~s}$ to $25 \% \mathrm{EG}+25 \%$ DMSO before vitrification. Ethyleneglycol was also used by Chian et al. (2004) to vitrify cumulus-free bovine oocytes in combination with PrOH or DMSO. Cleavage rates were similar for both CPA solutions, although $\mathrm{EG}+\mathrm{PrOH}$ gave higher blastocyst rates than EG + DMSO. 
There are few studies about oocyte vitrification using GLY alone. Buffalo oocytes vitrified with 51.1\% GLY in the absence of other cryoprotectants yield 23.5\% maturation rate after thawing (Wani et al. 2004).

One approach to reduce the negative impact of the CPAs on oocyte survival is the inclusion of non-toxic cryoprotectants, such as sugars (sucrose, glucose, trehalose, sorbitol or raffinose), in the cryopreservation media. Thus, sucrose is included in many vitrification protocols to counteract the osmotic effect (Vajta et al. 1998). An approach that can also reduce the toxic effect or the volume changes exerted by CPAs at high concentrations may be attained by stepwise addition/removal of CPAs (Prentice and Anzar 2011).

\section{Effect solution}

The stability of intracellular membranes and the plasmalemma during dehydration is very sensitive to high solute concentration. Because sodium is the most represented solute in freezing mixtures, it has been suggested that replacing this element with the cation choline, which does not diffuse through the plasmalemma, could significantly reduce the detrimental effects of high solute concentration on oocyte viability. On this basis, in a slow-cooling study performed on mouse oocytes, Stachecki et al. (1998) investigated the effects of replacing the sodium with equimolar amounts of choline. The authors found that the rates of survival, fertilization and development were very poor in the presence of high sodium concentration, but were maximal after replacing sodium with choline. An association between choline-based media and high post-thaw survival has been subsequently reported, confirming the above-referred experiment (Stachecki and Willadsen 2000). However, in bovine oocytes, we did not observe any improvement on frozen/thawed bovine MII oocytes, that showed a seriously compromised developmental ability with no development beyond the 5-8 cell stage (Diez et al. 2006)

\section{Metabolism}

Impact of oocyte cryopreservation procedures can be evaluated by morphology after warming, and in vitro embryo development after fertilization. These approaches provide limited information regarding the physiology of the oocyte and how CPAs and cooling rates impact cell function (Coticchio et al. 2005, 2007). In mouse oocytes, slow freezing results in a significant decrease in the uptake of pyruvate, and although vitrification was also associated with a decrease in nutrient utilization by the oocyte compared with noncryopreserved controls, the decrease was significantly smaller than that induced by slow freezing, indicating that vitrification produces less stress on the cell (Gardner et al. 2007).

In bovine in vitro embryo culture, ROS production gradually increases up to the late morula stage, while in expanded blastocysts, ROS levels decrease to values similar to those measured in oocytes (Dalvit et al. 2005). It has been reported that the addition of high concentrations of cysteamine during IVM reduces the negative effects of the ROS and improves development of embryos derived from both fresh (Dalvit et al. 2005) and cryopreserved bovine oocytes (Kelly et al. 2006). Several studies on cryo-injury mechanisms in sperm showed that freezing/cooling alters the activity and stereospecificity of enzymes acting as anti-oxidants, such as catalase, glutathione peroxidase, superoxide dismutase or other scavengers, subsequently reducing their beneficial effects (Baumber et al. 2005; Gadea et al. 2005), although antioxidant addition to the IVF medium negatively affected this process in bovine (Blondin et al. 1997; Dalvit et al. 1998), suggesting that certain levels of ROS are necessary during IVF. Clearly, metabolic function of the cryopreserved oocytes remains largely unknown, and there is a need for a more systematic approach that could elucidate events that occur during cryopreservation.

\section{What is the Future?}

With the aim of improving oocyte survival rates after cryopreservation, different approaches have been developed pointing to the use of different quality criteria or the modification of several oocyte aspects for selecting the best oocytes.

\section{Oocyte quality}

Embryo development and subsequent implantation and healthy pregnancy and delivery rates can be affected because of deviations from normal oocyte morphology after warming. Although it is generally accepted that extracytoplasmic abnormalities of the oocyte do not affect embryo quality, Ebner et al. (2008) and Balaban and Urman (2006) reported delayed development of embryos derived from ovoid oocytes with abnormal cleavage pattern. In addition, cytoplasmic abnormalities such as central granulations and vacuoles may indicate genetic, epigenetic or metabolic defects that may increase the rates of morphologically and/or genetically abnormal embryos (Kahraman et al. 2000). In this sense, the use the polarized light microscopy (PLM) allows the estimation of the effects of cryopreservation on meiotic spindle, and selecting oocytes bearing higher potential to survive and develop after thawing (Caamaño et al. 2010). Thus, the assessment of the unaltered meiotic spindle after cryopreservation could be used as an indicator of post-thawing viability (De Santis et al. 2007; Magli et al. 2011). The morphological characteristics of the spindle in oocytes evaluated by PLM before freezing and after thawing were significantly correlated with those assessed by immunofluorescent staining after fixation (Chen et al. 2004; Caamaño et al. 2011). So, PLM could be a valuable tool to assess the freezing/vitrification process. However, the use of PLM with oocytes from farm animals to improve cryopreservation is not widespread.

\section{High hydrostatic pressure (HHP)}

Sublethal hydrostatic pressure stress treatment has been shown to improve survival and development following cryopreservation of oocytes, embryos, semen and 
embryonic stem cells (for review, see; Pribenszky and Vajta 2011). The hypothesis suggests that the pressure determines stressful conditions leading to cell production and accumulation of chaperone proteins such as heat shock proteins. These proteins could be beneficial to the cells during cryopreservation, which is also a stress inducing procedure. The level of pressure and its duration depend on the species and the type of gamete or embryonic developmental stage. For example, porcine oocytes optimally withstand pressure of only $20 \mathrm{MPa}$, whereas mouse blastocysts can survive pressure as high as $90 \mathrm{MPa}$ for $30 \mathrm{~min}$ (Du et al. 2008). In porcine in vitro matured oocytes, a treatment of $20 \mathrm{MPa}$ was compared with $40 \mathrm{MPa}$, showing that $20 \mathrm{MPa}$ was superior to $40 \mathrm{MPa}$, and both treatments were significantly better than a vitrified control not submitted to HHP (Pribenszky and Vajta 2011).

Preliminary works have been performed in our laboratory for analysing the effect of a pressure treatment on cryosurvival of bovine oocytes (Muñoz et al. 2010), showing that oocytes treated with $20 \mathrm{MPa}$ survived vitrification at rates comparable with untreated oocytes. Moreover, we did not find differences in the heat shock proteins (70 and 90) levels between treated and untreated oocytes (own data, unpublished).

\section{Intracytoplasmic sperm injection}

Although the mechanism of zona pellucida (ZP) hardening of cryopreserved oocytes is unclear, it can be caused by a premature release of cortical granule (Vincent et al. 1990) resulting in lower incidence of sperm penetration (Hochi et al. 1998). These structural changes causing lower fertility could be overcome by intracytoplasmic sperm injection (ICSI). Blastocyst development rates in the ICSI-fresh $(16 \%)$ and ICSIfrozen-thawed $(10 \%)$ groups were significantly lower than that of IVF control $(19 \%)$, but did not differ between frozen-thawed IVF and ICSI groups (Rho et al. 2004).

\section{Conclusion}

Although cryopreservation of bovine oocytes remains still a challenge, some encouraging results have been obtained. The modification of protocols and their adaptation to different species could provide promising results; however, we should not forget the possibility of improving them by modifying some oocyte traits, to increase its resistance to cryopreservation. More studies are needed to identify the more promising procedures that will be incorporated into the routine oocyte cryopreservation protocols.

\section{Acknowledgements}

Financial support: FEDER-INIA-RZ2008-0014; M. Muñoz is supported by RYC08-03454. The authors wish to thank D. Martin and S. Carrocera and the students E. Correia and B. Trigal for their help with the laboratory work.

\section{Conflict of interest}

None of the authors have any conflict of interest to declare.

\section{References}

Agarwal A, 2009: Current trends, biological foundations and future prospects of oocyte and embryo cryopreservation. Reprod Biomed Online 19, 126-140.

Agca Y, Liu J, Peter AT, Critser ES, Critser JK, 1998: Effect of developmental stage on bovine oocyte plasma membrane water and cryoprotectant permeability characteristics. Mol Reprod Dev 49, 408-415.

Albarracín JL, Morató R, Izquierdo D, Mogas T, 2005: Vitrification of calf oocytes: effects of maturation stage and prematuration treatment on the nuclear and cytoskeletal components of oocytes and their subsequent development. Mol Reprod Dev 72, 239-249.

Allworth AE, Albertini DF, 1993: Meiotic maturation in cultured bovine oocytes is accompanied by remodeling of the cumulus cell cytoskeleton. Dev Biol 158, 101112.

Aman RR, Parks JE, 1994: Effects of cooling and rewarming on the meiotic spindle and chromosomes of in vitro-matured bovine oocytes. Biol Reprod 50, 103-110.

Arav A, Shehu D, Mattioli M, 1993: Osmotic and cytotoxic study of vitrification of immature bovine oocytes. J Reprod Fertil 99, 353-358.

Arav A, Zeron Y, Leslie SB, Behboodi E, Anderson GB, Crowe JH, 1996: Phase transition temperature and chilling sensitivity of bovine oocytes. Cryobiology 33, 589-599.
Arav A, Pearl M, Zeron Y, 2000: Does membrane lipid profile explain chilling sensitivity and membrane lipid phase transition of spermatozoaand oocytes? Cryo Letters 21, 179-186.

Arav A, Yavin S, Zeron Y, Natan D, Dekel I, Gacitua H, 2002: New trends in gamete's cryopreservation. Mol Cell Endocrinol 187, 77-81.

Balaban B, Urman B, 2006: Effect of oocyte morphology on embryo development and implantation. Reprod Biomed Online 12, 608-615.

Baumber J, Ball BA, Linfor JJ, 2005: Assessment of the cryopreservation of equine spermatozoa in the presence of enzyme scavengers and antioxidants. Am J Vet Res 66, 772-779.

Blondin P, Coenen K, Sirard MA, 1997: The impact of reactive oxygen species on bovine sperm fertilizing ability and oocyte maturation. J Androl 18, 454 460.

Bogliolo L, Ariu F, Fois I, Rosati MT, Zedda G, Leoni S, Succu S, Pau S, Ledda S, 2007: Morphological and biochemical analysis of immature ovine oocytes vitrified with or without cumulus cells. Theriogenology 68, 1138-1149.

Caamaño JN, Muñoz M, Diez C, Gómez E, 2010: Polarized light microscopy in mammalian oocytes. Reprod Domest Anim 45(Suppl 2), 49-56.

Caamaño JN, Maside C, Gil MA, Muñoz M, Cuello C, Díez C, Sánchez-Osorio JR, Martín D, Gomis J, Vazquez JM, Roca J,
Carrocera S, Martinez EA, Gómez E, 2011: Use of polarized light microscopy in porcine reproductive technologies. Theriogenology 76, 669-677.

Checura CM, Seidel GE, 2007: Effect of macromolecules in solutions for vitrification of mature bovine oocytes. Theriogenology 67, 919-930.

Chen SU, Lien YR, Chen HF, Chao KH, Ho HN, Yang YS, 2000: Open pulled straws for vitrification of mature mouse oocytes preserve patterns of meiotic spindles and chromosomes better than conventional straws. Hum Reprod 15, 2598 2603.

Chen CK, Wang CW, Tsai WJ, Hsieh LL, Wang HS, Soong YK, 2004: Evaluation of meiotic spindles in thawed oocytes after vitrification using polarized light microscopy. Fertil Steril 82, 666-672.

Chian R, Kuwayama M, Tan L, Tan J, Kato O, Nagai T, 2004: High survival rate of bovine oocytes matured in vitro following vitrification. J Reprod Dev 50, 685-696.

Chung HM, Hong SW, Lim JM, Lee SH, Cha WT, Ko JJ, Han SY, Choi DH, Cha KY, 2000: In vitro blastocyst formation of human oocytes obtained from unstimulated and stimulated cycles after vitrification at various maturational stages. Fertil Steril 73, 545-551.

Coticchio G, Bonu MA, Bianchi V, Flamigni C, Borini A, 2005: Criteria to assess 
human oocyte quality after cryopreservation. Reprod Biomed Online 11, 421-427.

Coticchio G, Bonu MA, Sciajno R, Sereni E, Bianchi V, Borini A, 2007: Truths and myths of oocyte sensitivity to controlled rate freezing. Reprod Biomed Online 15, 24-30

Dalvit GC, Cetica PD, Beconi MT, 1998: Effect of alpha-tocopherol and ascorbic acid on bovine in vitro fertilization. Theriogenology 49, 619-627.

Dalvit G, Llanes SP, Descalzo A, Insani M, Beconi M, Cetica P, 2005: Effect of alphatocopherol and ascorbic acid on bovine oocyte in vitro maturation. Reprod Domest Anim 40, 93-97.

De Santis L, Coticchio G, Fusi FM, Papaleo E, Rabellotti E, Brigante C, Borini A, Ferrari A, 2007: Objective evaluation of the viability of cryopreserved oocytes. Reprod Biomed Online 15, 338-345.

Diez C, Duque P, Gómez E, Hidalgo CO, Tamargo C, Rodríguez A, Fernández L, de la Varga S, Fernández A, Facal N, Carbajo M, 2005: Bovine oocyte vitrification before or after meiotic arrest: effects on ultrastructure and developmental ability. Theriogenology 64, 317-333.

Diez C, Rodríguez A, Hidalgo CO, Tamargo C, Carbajo M, Fernández L, Facal N, Caamaño JN, Duque P, Gómez E, 2006: Replacing sodium with choline chloride in the freezing medium for bovine oocytes does not improve cryosurvival. Reprod Domest Anim 41(Suppl. 2), 130.

Dinnyes A, Liu J, Nedambale TL, 2007: Novel gamete storage. Reprod Fertil Dev 19, 719-731.

Dinnyés A, Dai Y, Jiang S, Yang X, 2000: High developmental rates of vitrified bovine oocytes following parthenogenetic activation, in vitro fertilization, and somatic cell nuclear transfer. Biol Reprod 63, 513-518.

Du Y, Pribenszky CS, Molnár M, Zhang X, Yang H, Kuwayama M, Pedersen AM, Villemoes K, Bolund L, Vajta G, 2008: High hydrostatic pressure: a new way to improve in vitro developmental competence of porcine matured oocytes after vitrification. Reproduction 135, 13-17.

Ebner T, Moser M, Shebl O, Sommerguber M, Tews G, 2008: Prognosis of oocytes showing aggregation of smooth endoplasmic reticulum. Reprod Biomed Online 16, 113-118.

Ebrahimi B, Valojerdi MR, Eftekhari-Yazdi P, Baharvand H, 2011: Ultrastructural changes of sheep cumulus-oocyte complexes following different methods of vitrification. Zygote 17, 1-13.

Fujihira T, Nagai H, Fukui Y, 2005: Relationship between equilibration times and the presence of cumulus cells, and effect of taxol treatment for vitrification of in vitro matured porcine oocytes. Cryobiology 51, 339-343.

Fuller B, Paynter S, 2004: Fundamentals of cryobiology in reproductive medicine. Reprod Biomed Online 9, 680-691.

Gadea J, Garcia-Vasquez F, Matas C, Pardon JC, Canovas S, Gumbao D, 2005: Cooling and freezing of boar spermatozoa: supplementation of the freezing media with reduced glutathione preserves sperm function. J Androl 26, 396-404.
Gardner DK, Sheehan CB, Rienzi L, KatzJaffe M, Larman MG, 2007: Analysis of oocyte physiology to improve cryopreservation procedures. Theriogenology 67 64-72.

Gasparrini B, Attanasio L, De Rosa A, Monaco E, Di Palo R, Campanile G, 2007: Cryopreservation of in vitro matured buffalo (Bubalus bubalis) oocytes by minimum volumes vitrification methods Anim Reprod Sci 98, 335-342.

Gupta MK, Uhm SJ, Lee HT, 2007: Cryopreservation of immature and in vitro matured porcine oocytes by solid surface vitrification. Theriogenology 67, 238-248

Hochi S, Ito K, Hirabayashi M, Ueda M, Kimura K, Hanada A, 1998: Effect of nuclear stages during IVM on the survival of vitrified-warmed bovine oocytes. Theriogenology 49, 787-796.

Hochi S, Kato M, Ito K, Hirabayashi M, Ueda M, Sekimoto A, Nagao Y, Kimura K, Hanada A, 2000: Nuclear transfer in cattle : effect of linoleic acid-albumin on freezing sensitivity of enucleated oocytes. J Vet Med Sci 62, 1111-1113.

Hochi S, Akiyama M, Minagawa G, Kimura K, Hanada A, 2001: Effects of cooling and warming rates during vitrification on fertilization of in vitro-matured bovine oocytes. Cryobiology 42, 69-73.

Holt WV, 2008: Cryobiology, wildlife conservation and reality. Cryo Letters 29, 43

Horvath G, Seidel GE Jr, 2006: Vitrification of bovine oocytes after treatment with cholesterol-loaded methyl-beta-cyclodextrin. Theriogenology 66, 1026-1033

Jin B, Kawai Y, Hara T, Takeda S, Seki S, Nakata Y, Matsukawa K, Koshimoto C, Kasai M, Edashige K, 2011: Pathway for the movement of water and cryoprotecants in bovine oocytes and embryos. Bio Reprod 85, 834-847.

Kahraman S, Yakin K, Donmez E, Samli H, Bahce M, Cengiz G, Sertyel S, Samli M, Imirzalioglu N, 2000: Relationship between granular cytoplasm of oocytes and pregnancy outcome following intracytoplasmic sperm injection. Hum Reprod $\mathbf{1 5}$ 2390-2393.

Kelly J, Kleemann D, Kuwayama M, Walker S, 2006: Effect of cysteamine on survival of bovine and ovine oocytes vitrified using the minimal volume cooling (MCV) cryotop method. Reprod Fertil Dev 18, 158

Kuwayama M, 2007: Highly efficient vitrification for cryopreservation of human oocytes and embryos: the Cryotop method. Theriogenology 67, 73-81.

Lane M, Gardner DK, 2001: Vitrification of mouse oocytes using a nylon loop. Mol Reprod Dev 58, 342-347.

Larman MG, Sheehan CB, Gardner DK, 2006: Calcium-free vitrification reduces cryoprotectant-induced zona pellucida hardening and increases fertilization rates in mouse oocytes. Reproduction 131, 5361.

Le Gal F, Massip A, 1999: Cryopreservation of cattle oocytes: effects of meiotic stage, cycloheximide treatment, and vitrification procedure. Cryobiology 38, 290-300.

Ledda S, Leoni G, Bogliolo L, Naitana S, 2001: Oocyte cryopreservation and ovar- ian tissue banking. Theriogenology 55, 1359-1371.

Ledda S, Bogliolo L, Succu S, Ariu F, Bebbere D, Leoni GG, Naitana S, 2007: Oocyte cryopreservation: oocyte assessment and strategies for improving survival. Reprod Fertil Dev 19, 13-23.

Li GP, Bunch TD, White KL, Rickords L, Liu Y, Sessions BR, 2006: Denuding and centrifugation of maturing bovine oocytes alters oocyte spindle integrity and the ability of cytoplasm to support parthenogenetic and nuclear transfer embryo development. Mol Reprod Dev 73, 446 451

Liebermann J, Tucker MJ, 2002: Effect of carrier system on the yield of human oocytes and embryos as assessed by survival and developmental development after vitrification. Reproduction 124, 483-489.

Lim JM, Ko JJ, Hwang WS, Chung HM, Niwa K, 1999: Development of in vitro matured bovine oocytes after cryopreservation with different cryoprotectants. Theriogenology 51, 1303-1310.

Liu Y, Du Y, Lin L, Li J, Kragh PM, Kuwayama M, Bolund L, Yang H, Vajta G, 2008: Comparison of efficiency of open pulled straw (OPS) and Cryotop vitrification for cryopreservation of in vitro matured pig oocytes. Cryo Letters 29, 315-320.

Magli MC, Capoti A, Resta S, Stanghellini I, Ferraretti AP, Gianaroli L, 2011: Prolonged absence og meiotic spindles by birrefrincence imaging negatively affects normal fertilization and embryo development. Reprod Biomed Online 23, 747754.

Magnusson V, Feitosa WB, Goissis MD, Yamada C, Tavares LM, D'Avila-Assumpção ME, Visintin JA, 2008: Bovine oocyte vitrification: effect of ethylene glycol concentrations and meiotic stages. Anim Reprod Sci 106, 265-273.

Men H, Monson RL, Rutledge JJ, 2002: Effect of meiotic stages and maturation protocols on bovine oocyte's resistance to cryopreservation. Theriogenology $\mathbf{5 7}$, 1095-1103.

Men H, Monson RL, Parrish JJ, Rutledge JJ, 2003: Detection of DNA damage in bovine metaphase II oocytes resulting from cryopreservation. Mol Reprod Dev 64, 245-250.

Mermillod P, Tomanek M, Marchal R, Meijer L, 2000: High developmental competence of cattle oocytes maintained at the germinal vesicle stage for $24 \mathrm{~h}$ in culture by specific inhibition of MPF kinase activity. Mol Reprod Dev 55, 8995.

Modina S, Beretta M, Lodde V, Lauria A, Luciano AM, 2004: Cytoplasmic changes and developmental competence of bovine oocytes cryopreserved without cumulus cells. Eur J Histochem 48, 337-346.

Morató R, Izquierdo D, Paramio MT, Mogas T, 2008a: Cryotops versus openpulled straws (OPS) as carriers for the cryopreservation of bovine oocytes: effects on spindle and chromosome configuration and embryo development. Cryobiology 57, 137-141. 
Morató R, Izquierdo D, Paramio MT, Mogas T, 2008b: Embryo development and structural analysis of in vitro matured bovine oocytes vitrified in flexipet denuding pipettes. Theriogenology 70, 15361543.

Morató R, Mogas T, Maddox-Hyttel P, 2008c: Ultrastructure of bovine oocytes exposed to Taxol prior to OPS vitrification. Mol Reprod Dev 75, 1318-1326.

Mullen SF, Agca Y, Broermann DC, Jenkins CL, Johnson CA, Critser JK, 2004: The effect of osmotic stress on the metaphase II spindle of human oocytes, and the relevance to cryopreservation. Hum Reprod 19, 1148-1154

Muñoz M, Gómez E, Trigal B, Caamaño JN, Carrocera S, Martín D, Díez C, 2010: Survival of bovine oocytes to vitrification after hydrostathic sublethal pressure treatment. 1st Int. Congress on Controversies in Cryopreservation of Stem Cells, Reproductive cells, Tissue and organs Valencia (Spain) Proceedings pp 42.

Otoi T, Yamamoto K, Koyama N, Suzuki T, 1995: In vitro fertilization and development of immature and mature bovine oocytes cryopreserved by ethylene glycol with sucrose. Cryobiology 32, 455-460.

Papis K, Shimizu M, Izaike Y, 2000: Factors affecting the survivability of bovine oocytes vitrified in droplets. Theriogenology 54, 651-658.

Park MS, Chung HM, Cha KY, Hwang WS, Lee ES, Lim JM, 2001: Cryopreservation of ICR mouse oocytes: improved postthawed preimplantation development after vitrification using taxol, a cytoskeleton stabilizer. Fertil Steril 75, 1177-1184.

Paynter SJ, 2005: A rational approach to oocyte cryopreservation. Reprod Biomed Online 10, 578-586.

Pedro PB, Zhu SE, Makino N, Sakurai T, Edashige K, Kasai M, 1997: Effects of hypotonic stress on the survival of mouse oocytes and embryos at various stages. Cryobiology 35, 150-158.

Pereira RM, Marques CC, 2008: Animal oocyte and embryo cryopreservation. Cell Tissue Bank 9, 267-277.

Prentice JR, Anzar M, 2011: Cryopreservation of Mammalian oocyte for conservation of animal genetics. Vet Med Int 21, pii: 146405 .

Prentice JR, Singh J, Dochi O, Anzar M, 2011: Factors affecting nuclear maturation, cleavage and embryo development of vitrified bovine cumulus-oocyte complexes. Theriogenology 75, 602-609.

Pribenszky C, Vajta G, 2011: Cells under pressure: how sublethal hydrostatic pressure stress treatment increases gametes' and embryos' performance? Reprod Fertil Dev 23, 48-55.

Rall WF, Fahy GM, 1985: Ice-free cryopreservation of mouse embryos at $-196^{\circ} \mathrm{C}$ by vitrification. Nature 313, 573-575.

Rho GJ, Kim S, Yoo JG, Balasubramanian S, Lee HJ, Choe SY, 2002: Microtubulin configuration and mitochondrial distribu- tion after ultra-rapid cooling of bovin oocytes. Mol Reprod Dev 63, 464-470.

Rho GJ, Lee SL, Kim YS, Yeo HJ, Ock SA, Balasubramanian S, Choe SY, 2004: Intracytoplasmic sperm injection of frozenthawed bovine oocytes and subsequent embryo development. Mol Reprod Dev 68, 449-455.

Rojas C, Palomo MJ, Albarracin JL, Mogas T, 2004: Vitrification of immature and in vitro matured pig oocytes: study of distribution of chromosomes, microtubules, and actin microfilaments. Cryobiology 49 211-220.

Ruffing NA, Steponkus PL, Pitt RE, Parks JE, 1993: Osmometric behavior, hydraulic conductivity, and incidence of intracellular ice formation in bovine oocytes at different developmental stages. Cryobiology 30, 562-580.

Ruppert-Lingham CJ, Paynter SJ, Godfrey J, Fuller BJ, Shaw RW, 2006: Membrane integrity and development of immature murine cumulus-oocyte complexes following slow cooling to -60 degrees $\mathrm{C}$ : the effect of immediate rewarming, plunging into LN2 and two-controlled-rate-stage cooling. Cryobiology 52, 219-227.

Saragusty J, Arav A, 2011: Current progress in oocyte and embryo cryopreservation by slow freezing and vitrification. Reproduction 141, 1-19.

Schmidt DW, Nedambale TL, Kim C, Maier DB, Yang XJ, Tian XC, 2004: Effect of cytoskeleton stabilizing agents on bovine matured oocytes following vitrification. Fertil Steril 82, S26.

Seidel GE Jr, 2006: Modifying oocytes and embryos to improve their cryopreservation. Theriogenology 65, 228-235.

Seki S, Mazur P, 2008: Effect of warming rate on the survival of vitrified mouse oocytes and on the recrystallization of intracellular ice. Biol Reprod 79, 727737.

Shaw JM, Jones GM, 2003: Terminology associated with vitrification and other cryopreservation procedures for oocytes and embryos. Hum Reprod Update 9, 583-605.

Shaw JM, Oranratnachai A, Trounson AO, 2000: Fundamental cryobiology of mammalian oocytes and ovarian tissue. Theriogenology 53, 59-72.

Stachecki JJ, Willadsen SM, 2000: Cryopreservation of mouse oocytes using a medium with low sodium content: effect of plunge temperature. Cryobiology 40, 4-12.

Stachecki JJ, Cohen J, Willadsen SM, 1998: Cryopreservation of unfertilized mouse oocytes: the effect of replacing sodium with choline in the freezing medium. Cryobiology 37, 346-354.

Széll A, Shelton JN, Széll K, 1989: Osmotic characteristics of sheep and cattle embryos. Cryobiology 26, 297-301.

Tharasanit T, Colenbrander B, Stout T, 2006: Effect of maturation stage at cryopreservation on post-thaw cytoskeleton quality and fertilizability of equine oocytes. Mol Reprod Dev 73, 627-637.

Vajta G, Holm P, Kuwayama M, Booth PJ, Jacobsen H, Greve T, Callesen H, 1998: Open pulled straw (OPS) vitrification: a new way to reduce cryoinjuries of bovine ova and embryos. Mol Reprod Dev 51, 53-58.

Vieira AD, Mezzalira A, Barbieri DP, Lehmkuhl RC, Rubin MI, Vajta G, 2002: Calves born after open pulled straw vitrification of immature bovine oocytes. Cryobiology 45, 91-94.

Vincent C, Pickering SJ, Johnson MH, 1990 The hardening effect of dimethylsulphoxide on the mouse zona pellucida requires the presence of an oocyte and is associated with a reduction in the number of cortical granules present. J Reprod Fertil 89, 253-259.

Wang X, Al Naib A, Sun DW, Lonergan P 2010: Membrane permeability characteristics of bovine oocytes and development of a step-wise cryoprotectant adding and diluting protocol. Cryobiology 61, 58-65.

Wani NA, Misra AK, Maurya SN, 2004 Maturation rates of vitrified-thawed immature buffalo (Bubalus bubalis) oocytes: effect of different types of cryoprotectants. Anim Reprod Sci 84, 327-335.

Woods EJ, Benson JD, Agca Y, Critser JK, 2004: Fundamental cryobiology of reproductive cells and tissues. Cryobiology 48 , 146-156.

Yamada C, Caetano HV, Simões R, Nicacio AC, Feitosa WB, Assumpção ME, Visintin JA, 2007: Immature bovine oocyte cryopreservation: comparison of different associations with ethylene glycol, glycerol and dimethylsulfoxide. Anim Reprod Sci 99, 384-388.

Zeron Y, Pearl M, Borochov A, Arav A, 1999: Kinetic and temporal factors influence chilling injury to germinal vesicle and mature bovine oocytes. Cryobiology 38, 35-42.

Zeron Y, Sklan D, Arav A, 2002: Effect of polyunsaturated fatty acid supplementation on biophysical parameters and chilling sensitivity of ewe oocytes. Mol Reprod Dev 61, 271-278.

Zhou XL, Al Naib A, Sun DW, Lonergan P 2010: Bovine oocyte vitrification using the Cryotop method: effect of cumulus cells and vitrification protocol on survival and subsequent development. Cryobiology 61, 66-72.

Submitted: 21 Dec 2011; Accepted: 17 Feb 2012

Author's address (for correspondence): C Díez, Centro de Biotecnología AnimalSERIDA, Camino de Rioseco 1225, La Olla-Deva. 33394 Gijón, Spain.

E-mail: mcdiez@serida.org 
Copyright of Reproduction in Domestic Animals is the property of Wiley-Blackwell and its content may not be copied or emailed to multiple sites or posted to a listserv without the copyright holder's express written permission. However, users may print, download, or email articles for individual use. 